Article

\title{
A Study of Prediction Model Improvement for Air-Oxidation Breakaway in a Postulated Spent Nuclear Fuel Pool Complete Loss of Coolant Accident
}

\author{
Sanggil Park ${ }^{1}$, Jaeyoung Lee ${ }^{2}$ and Min Bum Park ${ }^{3, *}$ \\ 1 Nuclear Energy Team, Lee \& Ko, Seoul 04532, Korea; sanggil.park@leeko.com \\ 2 School of Mechanical and Control Engineering, Handong Global University, Pohang 37554, Korea; \\ jylee7@handong.edu \\ 3 Department of Energy and Chemical Engineering, Incheon National University, Incheon 22012, Korea \\ * Correspondence: mbpark@inu.ac.kr; Tel.: +82-32-835-8671
}

Citation: Park, S.; Lee, J.; Park, M.B. A Study of Prediction Model Improvement for Air-Oxidation Breakaway in a Postulated Spent Nuclear Fuel Pool Complete Loss of Coolant Accident. Sustainability 2021, 13, 1442. https://doi.org/10.3390/ su13031442

Received: 6 January 2021

Accepted: 27 January 2021

Published: 29 January 2021

Publisher's Note: MDPI stays neutral with regard to jurisdictional claims in published maps and institutional affiliations.

Copyright: (c) 2021 by the authors. Licensee MDPI, Basel, Switzerland. This article is an open access article distributed under the terms and conditions of the Creative Commons Attribution (CC BY) license (https:/ / creativecommons.org/licenses/by/ $4.0 /)$.

\begin{abstract}
The temperature of zirconium alloy cladding on the postulated spent nuclear fuel pool complete loss of coolant accident is abruptly increased at a certain time and the cladding is almost fully oxidized to weak $\mathrm{ZrO}_{2}$ in the air. This abrupt temperature escalation phenomenon induced by the air-oxidation breakaway is called a zirconium fire. Although an air-oxidation breakaway kinetic model correlated between time and temperature has been implemented in the MELCOR code, it is likely to bring about unexpected large errors because of many limitations of model derivation. This study suggests an improved time-temperature correlated kinetic model using the Johnson-Mehl equation. It is based on that the air-oxidation breakaway is initiated by the phase transformation from the tetragonal to monoclinic $\mathrm{ZrO}_{2}$ at the oxide-metal interface in the cladding. This new model equation is also evaluated with the Zry-4 air-oxidation literature data. This equation resulted in the almost similar air-oxidation breakaway timing to the actual experimental data at $800{ }^{\circ} \mathrm{C}$. However, at $1000{ }^{\circ} \mathrm{C}$, it showed an error of about $8 \mathrm{~min}$. This could be inferred from the influence of the $\mathrm{ZrN}$ phase change due to the nitrogen existing in air.
\end{abstract}

Keywords: zirconium fire; air-oxidation breakaway; spent fuel pool; phase transformation; Johnson-Mehl equation

\section{Introduction}

A risk of spent fuel pool (SFP) accidents has been significantly recognized since the Fukushima Daiichi nuclear disaster in 2011. The spent fuel pool in Unit 4 of the Fukushima Daiichi nuclear power plants was damaged by an extreme seismic event and subsequent flooding by a tsunami. Since then, many studies have been performed on the analysis of SFP accident scenarios [1-9]. Recently, the experimental program to investigate consequences of a complete loss of coolant accident (LOCA) in the SFP $(17 \times 17$ pressurized water reactor (PWR) spent fuel assembly configuration) was conducted in the frame of Organization for Economic Cooperation and Development/Nuclear Energy Agency (OECD/NEA) Sandia Fuel Project (SFP project; hereinafter) [10-13]. In addition, $9 \times 9$ boiling water reactor (BWR) spent fuel assembly tests were performed in a postulated complete LOCA [14]. From both SFP complete LOCA experiments, it was observed that zirconium alloy cladding temperature was abruptly increased at a certain point and the cladding was almost fully oxidized. This phenomenon was called a "zirconium fire".

Figure 1 shows the post-test spent fuel assemblies severely degraded after the zirconium fire. The possible consequence of zirconium fire would be an uncontrolled mass release of source term to the SFP building and even to the environment. At the onset of the zirconium fire, the dramatic oxygen depletion was observed with a very high cladding temperature escalation $[12,14]$. As shown in Figure 2, the oxygen concentration was abruptly 
consumed, and the zirconium alloy cladding was immediately and intensively oxidized with a highly exothermic heat release. This sudden high amount of released heat might trigger the zirconium fire. The air-oxidation kinetics were changed from the parabolic to linear, even to the accelerated kinetics [15]. This behavior is the air-oxidation breakaway. For this reason, the air-oxidation breakaway phenomenon was assumed to be the direct cause for the zirconium fire with a very abrupt cladding temperature escalation. To capture this phenomenon, a time-temperature kinetic model (Equation (1)) was developed in MELCOR code and it is called the air-oxidation breakaway model [12-15].

$$
\mathrm{t}=\mathrm{T}^{-12.528} 10^{42.038}
$$

where $\mathrm{t}$ and $\mathrm{T}$ are the breakaway transition time in sec and the cladding temperature in $\mathrm{K}$, respectively.

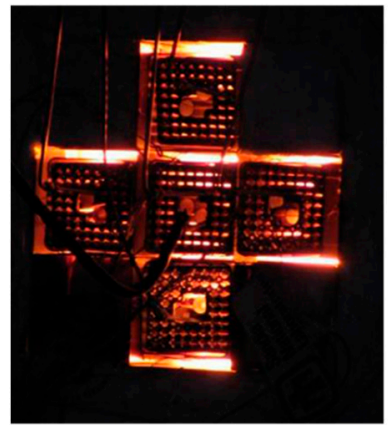

at zirconium ignition

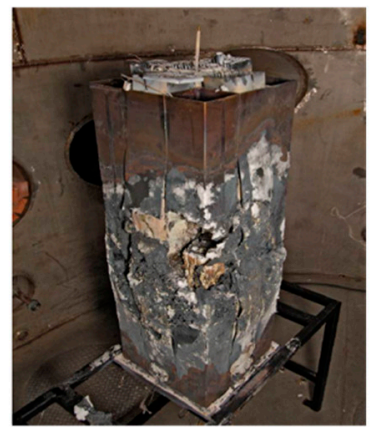

post-test assembly

SFP complete LOCA experiments

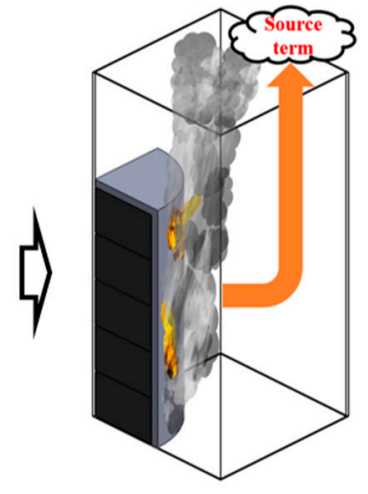

Consequence of zirconium ignition

Figure 1. Zirconium fire phenomenon during postulated SFP (spent fuel pool) complete LOCA (loss of coolant accident) experiments [12].

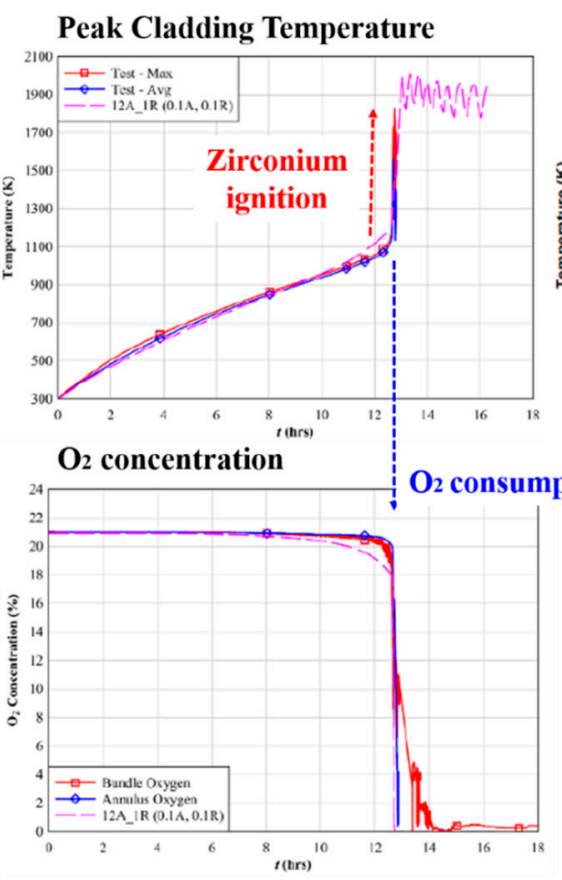

17x17 PWR Spent Fuel Assembly Test
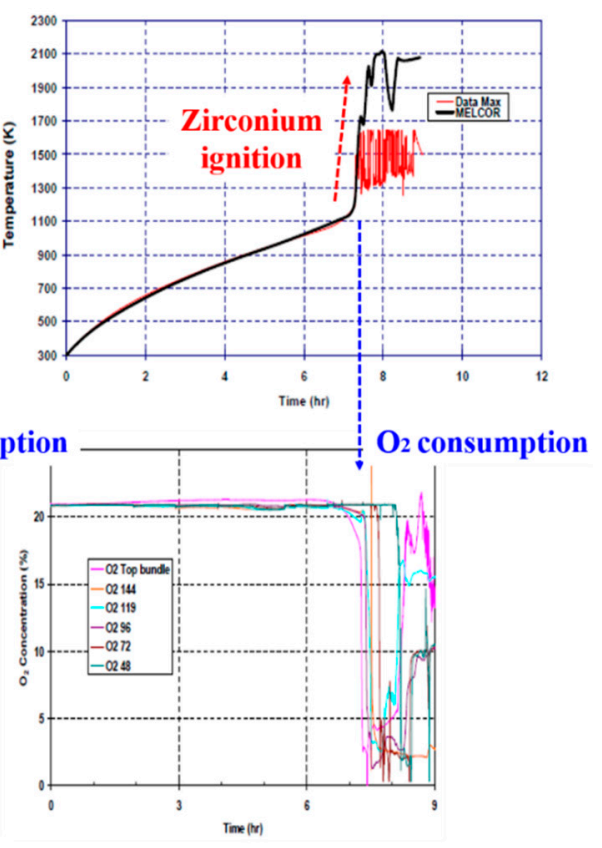

9x9 BWR Spent Fuel Assembly Test

Figure 2. Peak cladding temperature (top) and oxygen concentration (bottom) of SFP experiments [12,14], PWR—-pressurized water reactor, BWR-boiling water reactor. 
In our previous study, this current air-oxidation breakaway model was examined by comparing the SFP project test data with a series of MELCOR code sensitivity calculation results [16]. Since the current model is an empirical equation derived by introducing the concept of a lifetime function simply through log-log scale fitting using limited airoxidation experimental data, it has an uncertainty in which a tiny change $( \pm 3 \%)$ of model parameters induced a large difference in breakaway timing in comparison to the experimental data of the onset of zirconium fire. From this sensitivity analysis, we demonstrated that the current air-oxidation breakaway model should be improved by adopting the new formula of the model rather than previous log-log scale curve fitting.

In this study, based on the assumption that the breakaway occurs by the allotropic phase transformation, the possible way of model improvement is proposed. We suggest a new model equation that can more accurately predict the air-oxidation breakaway timing based on the Johnson-Mehl model.

\section{Development of the Improved Air-Oxidation Breakaway Model}

As mentioned above, the current air-oxidation breakaway model in MELCOR code was developed by the empirical fitting of limited data in the linearly correlated model in $\log -\log$ scale. This paper proposes the estimation of initiation of air-oxidation breakaway based on the assumption that the breakaway occurs by the allotropic phase transformation from tetragonal to monoclinic $\mathrm{ZrO}_{2}$ conversion at the oxide-metal interface when oxide thickness exceeds the critical oxide thickness [17-20]. The monoclinic $\mathrm{ZrO}_{2}$ phase becomes transformed to the tetragonal $\mathrm{ZrO}_{2}$ phase preferentially near the oxide-metal interface for the following reasons. First, the high compressive stress is accumulated near the oxidemetal interface by the growth of an oxide layer. Second, the grain size near the oxide-metal interface is rather small, and it is more suitable for the nucleation of the tetragonal oxide phase than the monoclinic oxide phase. Third, the presence of vacancies near the oxidemetal interface also promotes the monoclinic to tetragonal $\mathrm{ZrO}_{2}$ transformation. By a combination of the above three reasons, the phase transformation occurs from monoclinic to tetragonal $\mathrm{ZrO}_{2}$. As the oxide thickness grows, the stress is evolved due to the misfit strain for $\mathrm{Zr}$ clad tube and $\mathrm{ZrO}_{2}$. The Pilling-Bedworth ratio (PBR) well describes this misfit between oxide and metal. The PBR is a ratio of the volume of oxide produced and volume of metal consumed. Between the $\mathrm{ZrO}_{2}$ and $\mathrm{Zr}$ clad tube the PBR is 1.56, and it results in a compressive stress in the oxide layer and a tensile stress in the $\mathrm{Zr}$ clad tube.

In order to develop the model that predicts the air-oxidation breakaway timing, literature regarding the phase transformation from tetragonal to monoclinic $\mathrm{ZrO}_{2}$ were investigated. Tsubakino et al. reported the relationship between the phase transformation (tetragonal to monoclinic) time and temperature using the Johnson-Mehl equation (Equation (2)) [21,22], which describes the time-transformation isotherms in alloy systems [23].

$$
\alpha=1-\exp \left(-b t^{\mathrm{n}}\right)
$$

where $\alpha$ is the degree of the transformation (i.e., fraction of the monoclinic phase), $t$ is time, and $\mathrm{b}$ and $\mathrm{n}$ are constants. The rate constant $(\mathrm{k})$ and $\alpha$ are related by the Arrhenius equation, and thus the modified Johnson-Mehl equation is as follows:

$$
\frac{\mathrm{d} \alpha}{\mathrm{dt}}=\mathrm{kf}(\alpha)=\operatorname{Aexp}\left(\frac{-\mathrm{E}}{\mathrm{RT}}\right) \mathrm{f}(\alpha)
$$

where $\mathrm{E}$ indicates the activation energy, $\mathrm{R}$ is the ideal gas constant, and $\mathrm{T}$ is the temperature. Equation (3) can be rewritten as follows:

$$
\frac{1}{\operatorname{Aexp}\left(\frac{-E}{R T}\right)} \int \frac{\mathrm{d} \alpha}{\mathrm{f}(\alpha)}=\int \mathrm{dt}
$$


At a certain degree of the transformation, the breakaway is assumed to be initiated. Thus, at a fixed value of $\alpha$, the breakaway timing $\left(t_{\alpha}\right)$ can be estimated as follows:

$$
\mathrm{t}_{\alpha}=\frac{\mathrm{B}}{\mathrm{A}} \exp \left(\frac{\mathrm{E}}{\mathrm{RT}}\right)+\mathrm{C}
$$

where $B=\int[d \alpha / f(\alpha)]$. The time to the onset of breakaway (i.e., time to kinetic transition) at the temperature range of 873-1273 K was reported by Institut de Radioprotection et Sûreté Nucléaire (IRSN) [24]. In order to validate the breakaway timing formula (Equation (5)) and find the new model parameters, it is fitted with the IRSN Zry-4 air-oxidation tests of 23 data as shown in Figure 3 [24]. Therefore, the equation of air-oxidation breakaway timing is presented as follows:

$$
\mathrm{t}_{\text {breakaway }}=0.002293 \exp \left(\frac{14,220}{\mathrm{~T}}\right)+671.2
$$

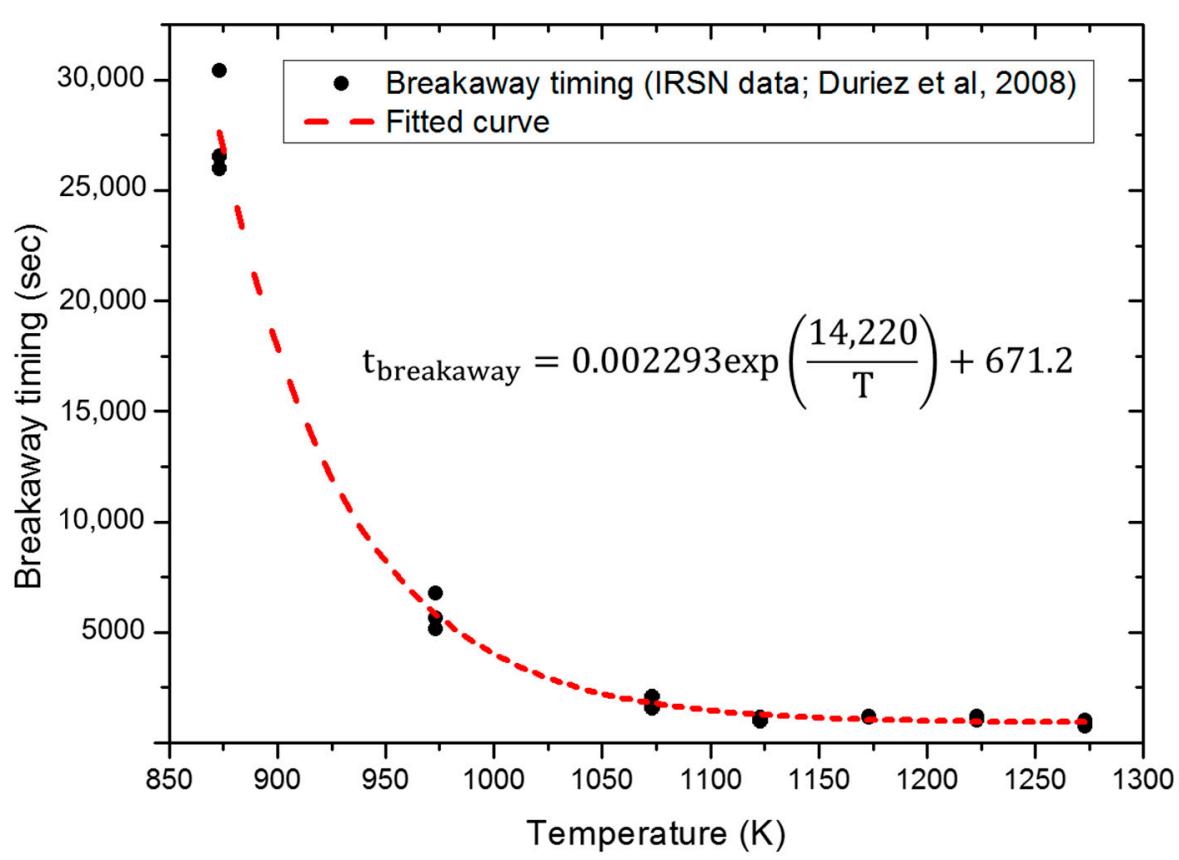

Figure 3. Fitted air-oxidation breakaway timing with IRSN (Institut de Radioprotection et Sûreté Nucléaire) data [24].

This newly proposed air-oxidation breakaway model (Equation (6)) to predict the timing of air-oxidation breakaway is different from the existing model (Equation (1)). It used the air-oxidation breakaway timing-temperature data for curve-fitting but not loglog scale by simply applying the Arrhenius' rate law theory, which is an empirical equation.

\section{Evaluation of the Newly Suggested Air-Oxidation Breakaway Model and Its Limitations}

In order to further evaluate the applicability of the newly proposed model of airoxidation breakaway timing, Equation (6) is applied to the other Zry-4 oxygen-nitrogen mixture oxidation breakaway timing data reported by Karlsruhe Institute of Technology (KIT) [25]. The calculated air-oxidation breakaway timings are 1975 and $834 \mathrm{sec}$ at 800 and $1000{ }^{\circ} \mathrm{C}$, respectively. As shown in Figure 4, the KIT data show the breakaway timings of ca. 2000 and $900 \mathrm{sec}$ at 800 and $1000{ }^{\circ} \mathrm{C}$, respectively. At $800{ }^{\circ} \mathrm{C}$, the breakaway timing of 20:80 oxygen-nitrogen mixture, which is approximate air composition, is very comparable with the calculated value. On the other hand, it had around $8 \mathrm{~min}$ difference at $1000{ }^{\circ} \mathrm{C}$ between KIT data and the calculated timing for 20:80 oxygen-nitrogen mixture. It seems 
that the nitrogen content did not apparently affect the breakaway timing at $800{ }^{\circ} \mathrm{C}$, but it slightly affected the breakaway timing at $1000^{\circ} \mathrm{C}$. It was reported that nitriding is much more pronounced at 1000 than $800{ }^{\circ} \mathrm{C}$ [26].
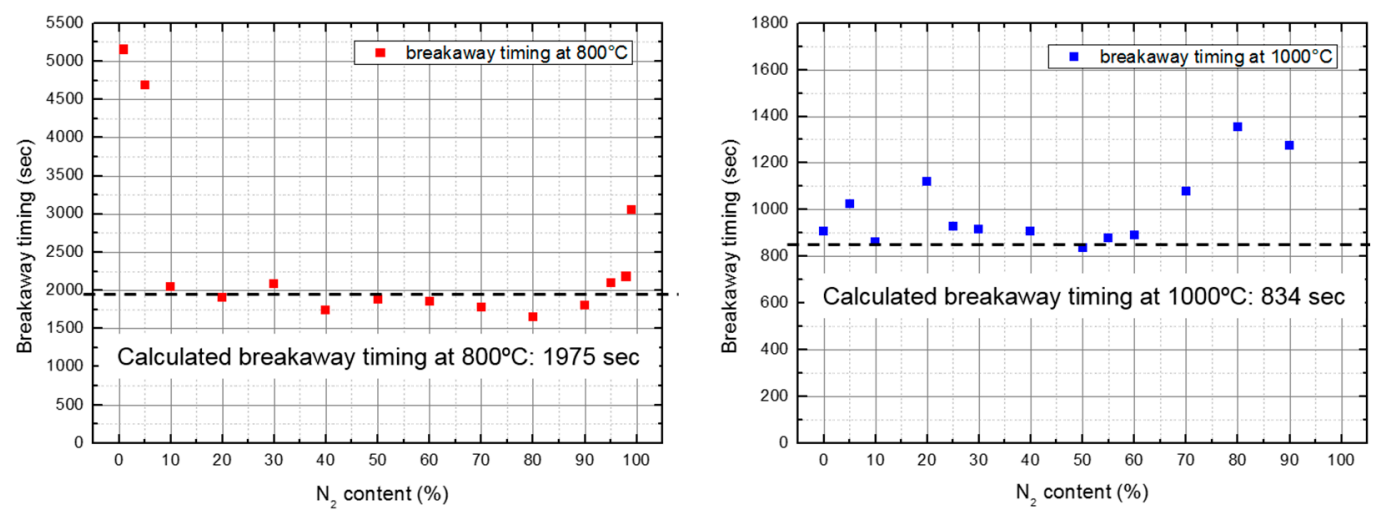

Figure 4. Breakaway timing of oxygen-nitrogen mixture oxidation [25].

Figure 5 shows the post-test Zry-4 oxidized samples at 800 and $1000{ }^{\circ} \mathrm{C}$ in 20:80 oxygen-nitrogen mixture [25]. The optically golden-yellow colored inclusion in the oxide scale is the $\mathrm{ZrN}$ phase, which is clearly seen in the micrograph of the $1000{ }^{\circ} \mathrm{C}$ test. The effects of nitrogen on reaction kinetics during the air oxidation were well described in [26]. The first effect of nitrogen is an enhanced cladding degradation by forming a porosity in the mixed oxide-nitride layer due to their molar volume mismatch. In addition, the $\mathrm{ZrN}$ is readily re-oxidized in the presence of oxygen. This re-oxidation of $\mathrm{ZrN}$ to $\mathrm{ZrO}_{2}$ results in the significant volume expansion and severe demolition of the mixed oxide-nitride layer. The second effect of nitrogen is a promoted exothermic heat release. Through the porosity and/or the severely degraded oxide scale, the exothermic heat release to the atmosphere would be promoted, and it accelerates further cladding oxidation.
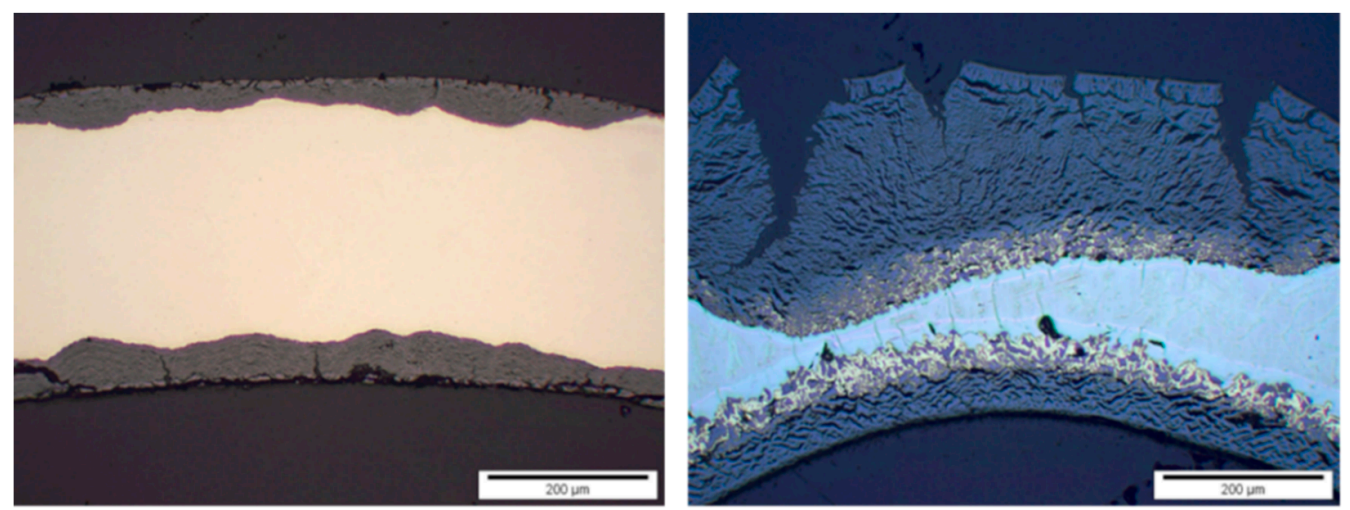

Figure 5. Micrographs of post-test Zry-4 20:80 $\mathrm{O}_{2}-\mathrm{N}_{2}$ mixture oxidized samples at $800{ }^{\circ} \mathrm{C}$ for $6 \mathrm{~h}($ left) and $1000^{\circ} \mathrm{C}$ for $1 \mathrm{~h}$ (right) [25].

However, the effect of nitrogen on the kinetic transition has been not reported in any literature. Further study should be required to understand the effect of nitrogen on the initiation of breakaway during air oxidation. If nitrogen affects the initiation of breakaway at a rather high temperature (e.g., $1000{ }^{\circ} \mathrm{C}$ ), the effect to nitrogen should be considered in the future modeling to predict the onset of air-oxidation breakaway.

\section{Conclusions}

In this study, a new kinetic model was proposed by considering the possible cause of the air-oxidation breakaway phenomenon in order to improve the weaknesses of the 
existing model. It has been known that the air-oxidation breakaway is initiated by the phase transformation from the tetragonal to monoclinic $\mathrm{ZrO}_{2}$ at the oxide-metal interface in the cladding. The newly proposed model adopted this phase transformation mechanism and developed the formulation using the Johnson-Mehl equation. This new model was validated with the available literature data of Zry-4 air-oxidation tests recently performed by IRSN and KIT. However, the new model considers no effect of nitrogen on the initiation of air-oxidation breakaway. Accordingly, the breakaway timing at $1000{ }^{\circ} \mathrm{C}$, where the phase change of $\mathrm{Zr}$ by nitrogen is more dominant, showed an error of about $8 \mathrm{~min}$ from the actual experimental data. Thus, further study should be required to address the active role of nitrogen, especially at high temperatures around and higher than $1000{ }^{\circ} \mathrm{C}$, on the air-oxidation kinetics and relevant model developments. Ultimately, we need to develop a kinetic model correlated between temperature and phase transformation (i.e., the thickness of $\mathrm{ZrO}_{2}$ ), excluding the time variable. The phase transformation from tetragonal to monoclinic $\mathrm{ZrO}_{2}$ seems a main reason to initiate the breakaway. At critical oxide thickness, the tetragonal phase is no longer stable and transforms to the monoclinic.

Author Contributions: Conceptualization, S.P. and M.B.P.; methodology, S.P. and M.B.P.; data analysis, S.P. and J.L.; investigation, S.P. and J.L.; writing-original draft preparation, S.P.; writingreview and editing, S.P. and M.B.P.; supervision, M.B.P.; project administration, S.P. and J.L.; funding acquisition, M.B.P. All authors have read and agreed to the published version of the manuscript.

Funding: This work was supported by the Basic Science Research Program through the National Research Foundation of Korea (NRF) funded by the Ministry of Science \& ICT (2019R1F1A1061214).

Institutional Review Board Statement: Not applicable.

Informed Consent Statement: Not applicable.

Data Availability Statement: Data sharing not applicable.

Conflicts of Interest: The authors declare no conflict of interest.

\section{References}

1. Fleurot, J.; Lindholm, I.; Kononen, N.; Ederli, S.; Jaeckel, B.; Kaliatka, A.; Duspiva, J.; Steinbrueck, M.; Hollands, T. Synthesis of spent fuel pool accident assessments using severe accident codes. Ann. Nucl. Energy 2014, 74, 58-71. [CrossRef]

2. Kaliatka, A.; Ognerubov, V.; Vileiniskis, V.; Uspuras, E. Analysis of the processes in spent fuel pool in case of loss of heat removal due to water leakage. Sci. Technol. Nucl. Ins. 2013, 2013, 1-11. [CrossRef]

3. Chen, S.R.; Lin, W.C.; Ferng, Y.M.; Chieng, C.C.; Pei, B.S. CFD simulating the transient thermal-hydraulic characteristics in a $17 \times 17$ bundle for a spent fuel pool under the loss of external cooling system accident. Ann. Nucl. Energy 2014, 73, 241-249. [CrossRef]

4. Chen, S.R.; Lin, W.C.; Ferng, Y.M.; Chieng, C.C.; Pei, B.S. Development of 3-D CFD methodology to investigate the transient thermal-hydraulic characteristics of coolant in a spent fuel pool. Nucl. Eng. Des. 2014, 275, 272-280. [CrossRef]

5. Jaeckel, B.; Birchley, J.; Fernandez-Moguel, L. Spent Fuel Pool under Severe Accident Conditions. Proceedings of 22nd International Conference on Nuclear Engineering, Prague, Czech Republic, 7-11, July, 2014.

6. Wu, X.; Li, W.; Zhang, Y.; Tian, W.; Su, G.; Qiu, S. Analysis of the loss of pool cooling accident in a PWR spent fuel pool with MAAP5. Ann. Nucl. Energy 2014, 72, 198-213. [CrossRef]

7. Groudev, P.; Stefanova, A.; Manolov, M. Investigation of dry out of SFP for VVER440/V230 at Kozloduy NPP. Nucl. Eng. Des. 2013, 262, 285-293. [CrossRef]

8. Wu, X.; Li, W.; Zhang, Y.; Tian, W.; Su, G. Analysis of accidental loss of pool coolant due to leakage in a PWR SFP. Ann. Nucl. Energy 2015, 77, 65-73. [CrossRef]

9. Carlos, S.; Sanchez-Saez, F.; Martorell, S. Use of TRACE best estimate code to analyze spent fuel storage pools safety. Prog. Nucl. Enegry 2014, 77, 224-238. [CrossRef]

10. Adorni, M.; Herranz, L.E.; Hollands, T.; Ahn, K.-I.; Bals, C.; D’Auria, F.; Horvath, G.L.; Jaeckel, B.S.; Kim, H.-C.; Lee, J.-J.; et al. OECD/NEA Sandia Fuel Project phase I: Benchmark of the ignition testing. Nucl. Eng. Des. 2016, 307, 418-430. [CrossRef]

11. Adormi, M.; Esmaili, H.; Grant, W.; Hollands, T.; Hózer, Z.; Jäckel, B.; Munoz, M.; Nakajima, T.; Rocchi, F.; Stručić, M.; et al. Status Report on Spent Fuel Pools under Loss-of-Cooling and Loss-of-Coolant Accident Conditions Final Report, NEA/CSNI/R(2015)2; OECD/NEA: Paris, France, 2015.

12. Durbin, S.G.; Lindgren, E.R.; Goldmann, A.S.; Zavisca, M.; Yuan, Z.; Karimi, R.; Krall, A.; Khatib-Rahbar, M.; Zigh, A.; Velazquez-Lozada, A.; et al. Spent Fuel Pool Project Phase I: Pre-Ignition and Ignition Testing of a Single Commercial 17×17 Pressurized 
Water Reactor Spent Fuel Assembly under Complete Loss of Coolant Accident Conditions; NUREG/CR-7215; US Nuclear Regulatory Commission: Rockville, MD, USA, 2016.

13. Durbin, S.G.; Lindgren, E.R.; Humphries, L.; Yuan, Z.; Zavisca, M.; Khatib-Rahbar, M.; Beaton, R.; Zigh, A.; Gonzalez, S. Spent Fuel Pool Project Phase II: Pre-Ignition and Ignition Testing of a $1 \times 4$ Commercial $17 \times 17$ Pressurized Water Reactor Spent Fuel Assembly under Complete Loss of Coolant Accident Conditions; NUREG/CR-7216; US Nuclear Regulatory Commission: Rockville, MD, USA, 2016.

14. Lindgren, E.R.; Durbin, S.G. Characterization of Thermal-Hydraulic and Ignition Phenomena in Prototypic, Full-Length Boiling Water Reactor Spent Fuel Pool Assemblies after a Postulated Complete Loss-of-Coolant Accident; NUREG/CR-7143; US Nuclear Regulatory Commission: Rockville, MD, USA, 2013.

15. Natesan, K.; Soppet, W.K. Air Oxidation Kinetics for Zr-Based Alloys; NUREG/CR-6846; US Nuclear Regulatory Commission: Rockville, MD, USA, 2014.

16. Park, S.; Park, M.B. The limitations of an air-oxidation breakaway model to predict a zirconium fire in a spent nuclear fuel pool accident. Sustainability 2019, 11, 6364. [CrossRef]

17. Idarraga, I.; Mermoux, M.; Duriez, C.; Crisci, A.; Mardon, J.P. Raman investigation of pre-and post-breakaway oxide scales formed on Zircaloy-4 and M5 ${ }^{\circledR}$ in air at high temperature. J. Nucl. Mater. 2012, 421, 1-3. [CrossRef]

18. Idarraga, I.; Mermoux, M.; Duriez, C.; Crisci, A.; Mardon, J.P. Potentialities of Raman imaging for the analysis of oxide scales formed on Zircaloy-4 and M5 ${ }^{\circledR}$ in air at high temperature. Oxid. Met. 2013, 79, 3-4. [CrossRef]

19. Yoo, H.-I.; Koo, B.-J.; Hong, J.-O.; Hwang, I.-S.; Jeong, Y.-H. A working hypothesis on oxidation kinetics of Zircaloy. J. Nucl. Mater. 2001, 299, 235-241. [CrossRef]

20. Causey, R.A.; Cowgill, D.F.; Nilson, R.H. Review of the Oxidation Rate of Zirconium Alloys; SAND2005-6006; Sandia National Laboratories: Albuquerque, NM, USA, 2005.

21. Tsubakino, H.; Hamamoto, M.; Nozato, R. Tetragonal-to-monoclinic phase transformation during thermal cycling and isothermal ageing in yttria-partially stabilized zirconia. J. Mater. Sci. 1991, 26, 5521-5526. [CrossRef]

22. Tsubakino, H.; Matsuura, N. Relationship between transformation temperature and time-temperature-transformation curves of tetragonal-to-monoclinic martensitic transformation in zirconia-yttria system. J. Am. Ceram. Soc. 2002, 85, 2102-2106. [CrossRef]

23. Sarkar, S.B.; Ray, H.S. Analysis of kinetic data by Johnson-Mehl equation. J. Therm. Anal. 1990, 36, 231-242. [CrossRef]

24. Duriez, C.; Dupont, T.; Schmet, B.; Enoch, F. Zircaloy-4 and M $5^{\circledR}$ high temperature oxidation and nitriding in air. J. Nucl. Mater. 2008, 380, 30-45. [CrossRef]

25. Steinbrueck, M.; Schaffer, S. High-temperature oxidation of Zircaloy-4 in oxygen-nitrogen mixtures. Oxid. Met. 2016, 85, 245-262. [CrossRef]

26. Park, S.; Fernandez-Moguel, L.; Prasser, H.M.; Birchley, J.; Steinbrueck, M.; Seifert, H.J. Effect of Nitriding during an Air Ingress Scenarios. Proceedings of TopFuel 2015, Zürich, Switzerland, 13-17, September, 2015. 